\title{
Survival analysis of banding and bonding molar tubes in adult patients over a 12-month period: a split-mouth randomized clinical trial
}

\begin{abstract}
Valéria Jacques OEIRAS(a) Valéria Assis Almeida e SILVA(a) Leidiana Aguiar AZEVEDO(a) Vanessa Soares LOBATO(a) David NORMANDO(a)
\end{abstract}

(a) Universidade Federal do Pará - UFPA, School of Dentistry, Department of Orthodontics, Belém, Pará, Brazil.

Declaration of Interests: The authors certify that they have no commercial or associative interest that represents a conflict of interest in connection with the manuscript.

\section{Corresponding Author:}

David Normando

E-mail: davidnormando@hotmail.com

DOI: 10.1590/1807-3107BOR-2016.vol30.0136

Submitted: Dec 24, 2015

Accepted for publication: Sep 23, 2016

Last revision: Oct 27, 2016
Abstract: This split-mouth randomized clinical trial aimed to compare the survival rate of bonding and banding molar tubes in adult orthodontic patients. Eligibility criteria included adults (aged $>18$ years), no active caries, restorations, or fractures in the upper and lower molars. The main outcome was any type of first-time failure in molar tubes. A computer-generated randomization scheme was used in a 1:1 ratio. The survival rate was estimated for 32 adult patients, in whom a tube was bonded to a molar tooth using composite resin on one side and a band was cemented with glass ionomer onto the same tooth in the contralateral arch. A total of 59 banded and 59 bonded molars were followed up for 12 months. Blinding was not applicable. Survival analysis including Cox regression was used at $p<0.05$. The survival rate of bonded molars was not statistically different from that of banded molars (log-rank test, $\mathrm{p}=0.97$ ). Hazard ratio (HR) was 0.72 (95\%CI, 0.38-1.31). Bonded upper molars yielded a survival rate of $81.25 \%$ (26 out of 32 ) compared to $71.87 \%$ (23 out of 32 ) for banded upper molars. The survival rate was $66.66 \%$ (18 out of 27 ) for banded lower molars and $59.25 \%$ for bonded lower molars (16 out of 27$)$. The HR for lower vs. upper arch was 2.16 (95\%CI, 1.18-3.98). No serious problem was observed other than gingivitis associated with plaque accumulation. In contrast to previous studies in young patients, in adults, bonding orthodontic tubes to molars is similar to molar banding. However, both procedures had a high failure rate in the lower arch.

Keywords: Orthodontic Appliances; Dental Bonding; Molar; Adult.

\section{Introduction}

Molar banding is a well-established procedure in orthodontics as it yields proper retention and resistance to orthodontic forces. As adhesive systems evolved, bonding attachments to molars has become a routine procedure, reducing the duration of clinical care and facilitating oral hygiene. ${ }^{1}$

Decalcification of the dental enamel is lower with bands than with tubes bonded with a light curing system. ${ }^{1,2}$ However, patient hygiene may be compromised, allowing for plaque accumulation and for the development of periodontal problems, which are more critical in 
adult patients. ${ }^{3}$ Another disadvantage of banding is the painful experience both before and during the procedure and the higher risk of bacteremia. ${ }^{4,5}$ Also, an additional appointment is necessary for prior separation of the adjacent teeth and fitting of the molar band.

Despite the advantages in terms of comfort, minor periodontal damage ${ }^{3}$ and shorter chair time, direct bonding of molars is not yet universally accepted among orthodontists. Randomized clinical trials ${ }^{2,6}$ validated by a systematic review ${ }^{7}$ have shown that failure of tubes bonded to molars is considerably higher than molars banded with glass ionomer cement. However, the vast majority of patients in these studies consisted of children and adolescents. This aspect is of paramount importance since patient age has a significant impact on the failure of orthodontic appliances. ${ }^{8}$

Assuming that data on the clinical efficiency of bonding of molar tubes in adult patients are still lacking and given that benefits are particularly more impactful in adult patients - because the discomfort caused by separating the teeth for banding is not present, in addition to other periodontal benefits, the aim of this study was to examine the survival rate of bonding vs. banding of molar tubes in adult patients.

\section{Specific objectives or hypotheses}

In this study, the null hypothesis was that there was no difference in the survival rate of bonding and banding of molar attachments in adult orthodontic patients after 12 months.

\section{Methodology}

This study was approved by the human research ethics committee of the Center for Health Sciences of the Federal University of Pará, under \# 12821413.0.0000.5174.

\section{Trial design and any changes after trial commencement}

A parallel-group, split-mouth randomized controlled trial was conducted with adult patients (age range 18-38 years, mean 26.5 years) using a
1:1 ratio. There were no changes to outcome after trial commencement.

\section{Participants, eligibility criteria, and settings}

Cases were treated consecutively at a graduate clinic from November 2010 to June 2013. Only Class I and Class II subjects were enrolled. No other restriction was imposed on malocclusion type. Patients had one quadrant randomly assigned for the placement of molar bands (banding) while the contralateral quadrant received bonded molar tubes (bonding). The opposite was done in the lower arch (Figure 1). Patient randomization was performed with BioEstat 5.3 (Mamirauá, Belém, Pará, Brazil) software.

The sample consisted of 32 adult patients ( 23 females and 9 males), totaling 118 molars (108 first molars and 10 second molars). After randomization, 59 molars were banded and another 59 molars received bonded tubes (Figure 2). Six patients were treated only in the upper arch and one patient only in the lower arch. The first fracture was recorded monthly for a period of 1 year. Patients with missing teeth in the molar area, restorations on the buccal surface of molars, and those requiring bands on the first and second molars due to the use of auxiliary devices were excluded from the sample.

\section{Interventions}

All procedures and techniques for the bonding and banding of orthodontic attachments were carried out

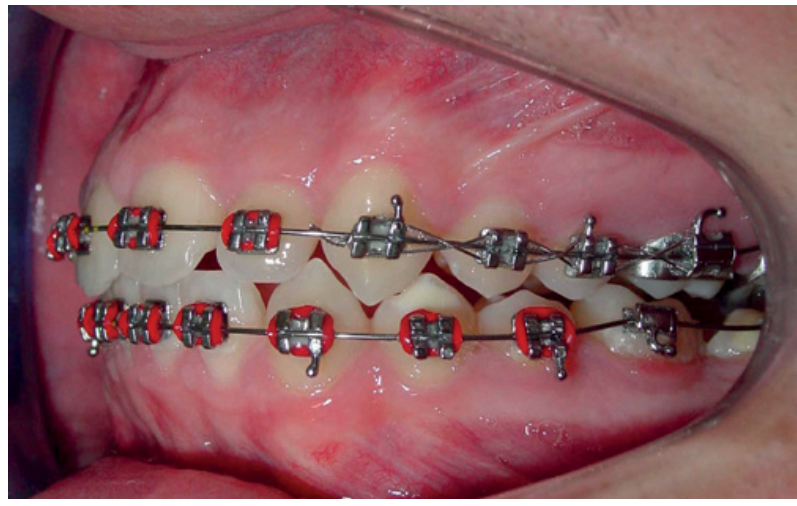

Figure 1. Patient with banded tubes on the first upper left (U6L) and first lower right (LR6) molars, and bonded tubes on the first upper right (U6R) and lower left molars. 


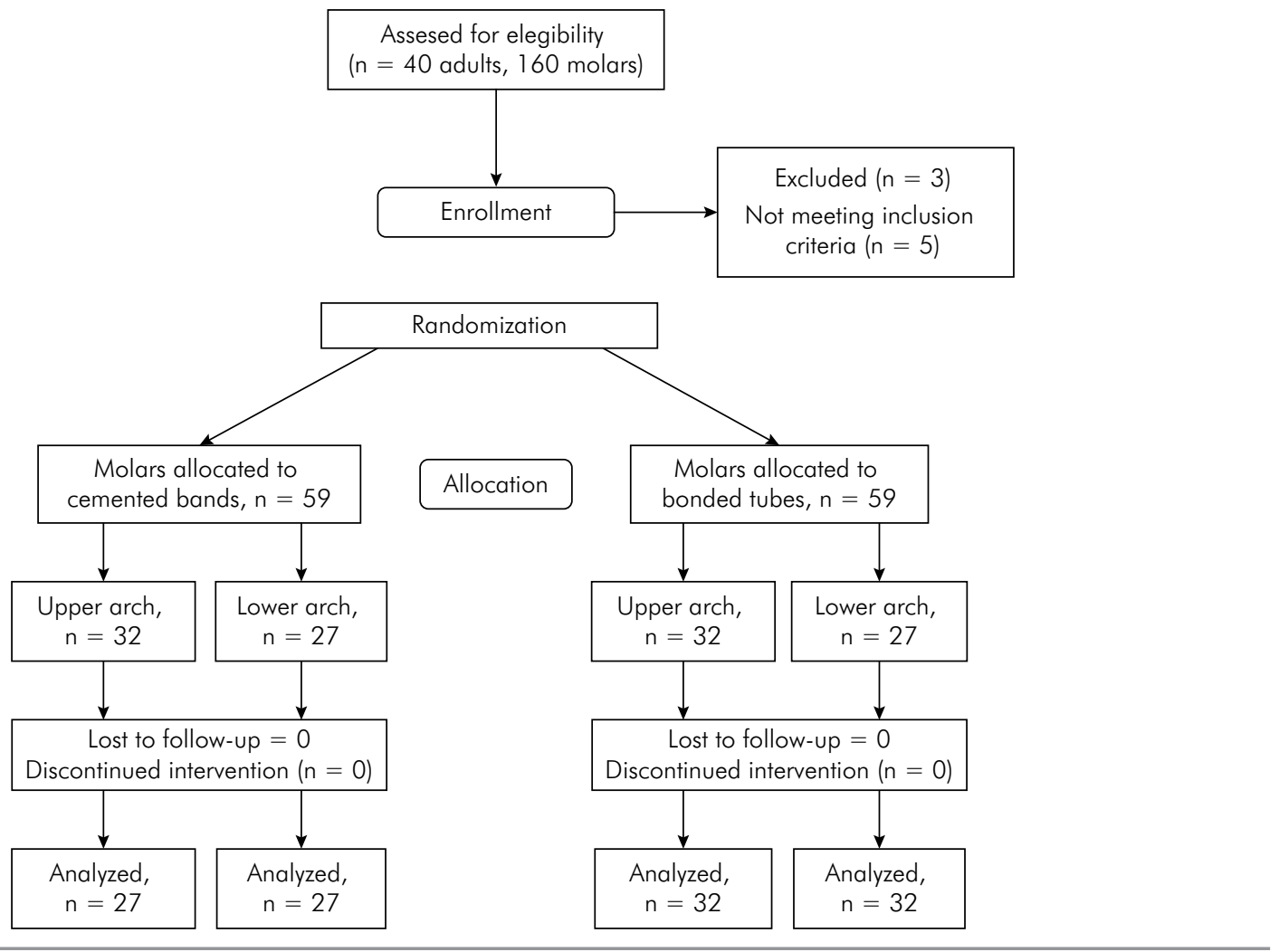

Figure 2. Sample randomization flowchart.

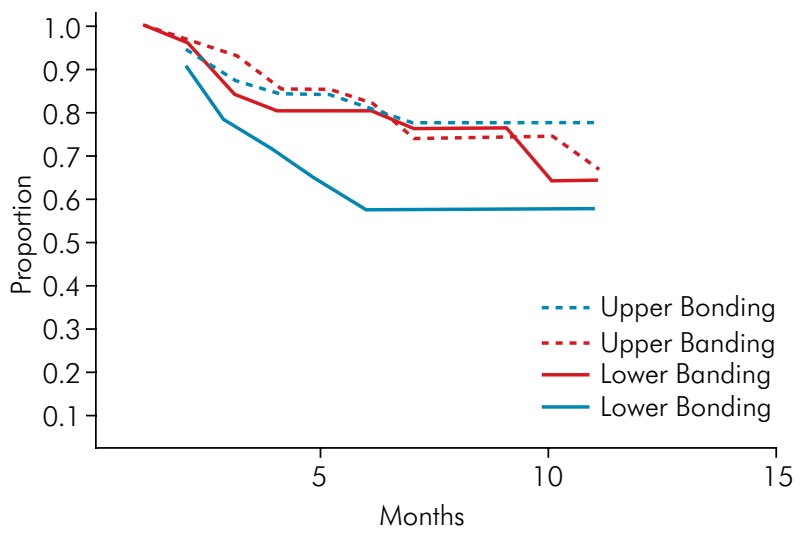

Figure 3 .Survival analysis for banded molars (red) and bonded molars (blue) in the upper (dashed line) and lower (solid line) arches.

according to the manufacturer's recommendations. Patients were treated with 0.022 " straight-wire brackets (Abzil- 3M, São José do Rio Preto, Brazil). Bands with pre-welded tubes (Abzil- 3M, São José do Rio Preto, Brazil) were cemented with self-curing glass ionomer cement (Precedent, Reliance, Itasca,
USA) and 80-micron base mesh tubes were bonded with light-curing adhesive (Light Bond, Reliance, Itasca - USA). Patients were treated by 12 orthodontic residents. When first molars were evaluated, second molar tubes were bonded bilaterally in $62 \%(n=62 \%)$ of cases.

\section{Outcomes and statistical analysis}

The main outcome was any first-time failure in the bonding or banding of molar attachments (Figure 3). Fracture occurrence, rather than percentage, was evaluated by log-rank survival analysis (Rosner's method) including Cox regression at $\mathrm{p}<0.05$. Blinding was not applicable.

\section{Sample size calculation}

Calculation of sample size was based on the ability to detect a clinically relevant difference in the risk of first-time failure (primary outcome) of $20 \%$ between the two trial arms $(5 \% \text { vs. } 25 \%)^{2,6}-\mathrm{a}=0.05$ and power of $80 \%$. This calculation indicated that 49 participants were required in each arm; this 
was rounded up to $59(20 \%)$ to account for losses to follow-up.

\section{Results}

No patient dropped out of treatment during the study period. This increased the ability to detect a clinically relevant difference between the two trial arms by $15 \%$.

During the 12 months of follow-up, 18 of 59 (30.5\%) banded molars showed failure compared to 17 of $59(28.8 \%)$ of bonded molars. The survival rate of bonded molars was not statistically different from that of banded molars (log-rank test, $p=0.97$ ). The data were analyzed on an intention-to-treat basis and the hazard ratio (HR) was 0.72 (95\% confidence interval [CI], 0.38-1.31). The bonded attachments showed the first failure within 2 months, on average, whereas the first fracture appeared on the banded attachments within 3 months (Table).

When the upper and lower arches were assessed separately, the survival rate of bonded upper molars was $81.25 \%$ (26 out of 32 ) and that of banded molars was $71.87 \%$ (23 out of 32$)(p=0.71)$. As regards the lower arch, the survival rate of banded molars was $66.66 \%$ (18 out of 27) and that of bonded molars was $59.25 \%$ (16 out of 27), not achieving a significant difference $(p=0.69)$. The HR for lower vs. upper failures was 2.16 (95\%CI: 1.18-3.98). No serious problem was observed other than gingivitis associated with plaque accumulation.

\section{Discussion}

Factors such as optimizing clinical (chair) time and patient comfort, as well as preserving the integrity of dental structures, are paramount to ensure the effectiveness of orthodontic treatment. As regards the duration of treatment, a recent study $^{9}$ showed that about $30 \%$ of the variation in treatment time in adult patients was related to orthodontic appliance failure. Frequent rebonding and/or recementation of attachments often interferes with orthodontic mechanics, eventually increasing treatment time. ${ }^{7,9}$

Given the advantages of bonding attachments for posterior teeth, such as reduced clinical time, esthetics, and lower risk of periodontal problems and bacteremia, most scientific research has been conducted to assess the efficiency of bonding in the molar region. The focus has been on the laboratory properties of the materials and adhesives used for bonding tubes to molar teeth. ${ }^{10-13}$ Prospective randomized clinical trials ${ }^{2,6}$ are an exception and essentially involve children and adolescents.

By comparing the overall survival rate of banded molars $(69.49 \%)$ with that of bonded molars $(71.18 \%)$ in adults, the results of this study revealed a survival rate that was not statistically different $(p=0.97)$. The failure rate in both alternatives was found to be similar, i.e., $30.5 \%$ (banded molars) vs. $28.8 \%$ (bonded molars). However, either procedure showed a higher rate of failure in the lower arch $(\mathrm{p}=0.01)$.

The failure rate of bonded molar tubes in the present study (28.8\%) was similar to what was observed in retrospective studies (14.8-29.5\%), ${ }^{8,14-17}$ and in a prospective study with adolescents (18.4-33.7\%). ${ }^{2,6}$ A previous study ${ }^{18}$ in which a single operator bonded all teeth showed that young patients (aged $<18$ years) had a greater risk than old ones (aged $>18$ years) and that there was no significant difference in failure when first molars

Table. Number of surviving bonding/ banding attachments in the upper and lower dental arches measured in months.

\begin{tabular}{lcccccccccccccc}
\hline Time (months) & 0 & 1 & 2 & 3 & 4 & 5 & 6 & 7 & 8 & 9 & 10 & 11 & 12 & No failure \\
\hline Bonding (Upper) & 32 & 31 & 29 & 28 & 28 & 27 & 26 & 26 & 26 & 26 & 26 & 26 & 26 & $81.25 \%$ \\
Bonding (Lower) & 27 & 26 & 22 & 20 & 18 & 16 & 16 & 16 & 16 & 16 & 16 & 16 & 16 & $59.25 \%$ \\
Bonding (Upp + low) & 59 & 57 & 51 & 48 & 46 & 43 & 42 & 42 & 42 & 42 & 42 & 42 & 42 & $71.18 \%$ \\
Banding (Upper) & 32 & 31 & 30 & 28 & 28 & 27 & 25 & 25 & 25 & 25 & 25 & 24 & 23 & $71.87 \%$ \\
Banding (Lower) & 27 & 26 & 23 & 22 & 22 & 22 & 21 & 21 & 21 & 18 & 18 & 18 & 18 & $66.66 \%$ \\
Banding (Upp + low) & 59 & 57 & 53 & 50 & 50 & 49 & 46 & 46 & 46 & 43 & 41 & 41 & 41 & $69.49 \%$ \\
\hline
\end{tabular}


are compared to second molars. In old and young patients, failure rates of molar tubes were $5.2 \%$ and $15.3 \%$, respectively. As regards the relative similarity in the success rate of bonding compared to previous randomized studies, ${ }^{2,6}$ a marked difference was found in the failure rate between banded molars, $2.6 \%^{2}$ and $18.8 \%{ }^{6}$, and the $30.5 \%$ found in this study. These differences may have been due to the materials used in these studies. It is more likely, however, that the different experience of each operator exercised a major influence on the whole process, as reported by a previous study that analyzed the bonding of molar tubes. ${ }^{8}$ As to banding, this finding seems to be intimately associated with moisture control, which is vital for the manipulation of glass ionomer cements used in the present study. In addition, orthodontic residents usually work without a chairside assistant, which impairs moisture control during banding and bonding procedures. Previous studies have also shown that the operator affects the bond strength of molar tubes. ${ }^{2,8}$

Despite the fact that the survival graph for upper and lower molars has shown a similar behavior between bonded and banded molars ( $p=0.97$ ), when the results are analyzed separately by dental arch, the bonding (81.25\%) and banding (71.87\%) techniques seem to exhibit greater strength in the maxillary vs. mandibular arch, $59.25 \%$ vs. $66.66 \%$, respectively. The survival curve for the lower molars shows evidence of a clinically significant difference between banding and bonding, which apparently results in a greater failure rate of bonded or banded tubes in the lower arch. However, similar survival rates tend to occur over time. These results warrant the need for long-term studies.

Other factors that may influence the effectiveness of molar attachments are the mechanics employed in the treatment and occlusal stress. ${ }^{1}$ In some orthodontic treatments, the use of orthodontic bands is essential when the case requires additional devices designed to receive a higher load due to the mechanics being utilized or to the presence of restored molars. Furthermore, some professionals choose to band the mandibular molars due to a higher incidence of occlusal forces in the lower arch. It would therefore be desirable to design methods to increase the efficiency of this process in teeth subjected to high-impact chewing, such as molars, by applying an additional resin layer on the occlusal surface of the tube/tooth interface, thereby improving the quality of the bond strength of bonded tubes. ${ }^{10,17}$

\section{Limitations}

This study has some limitations, which should be mentioned, including the presence of different operators, although each operator performed both bonding and banding. The results also are limited by the fact that the study involved relatively inexperienced operators, i.e., orthodontic residents who may find it hard to control moisture while handling and applying the materials. Furthermore, the data analysis should also be circumscribed to the materials used in the present study. Although different curing lights have been used for orthodontic bonding, there is no evidence to support the preference for one light cure type over another based on the risk of attachment failure. ${ }^{19}$ Failures in either bonded or banded tubes are an important variable and require further investigation given their likely influence on treatment time., ${ }^{9,20}$ Moreover, future studies on the survival rate of bonding and banding of molar attachments in adult patients should seek to assess periodontal changes and the occurrence of white spots and to perform a comparative analysis of operators with different levels of experience.

\section{Generalizability}

The generalizability of these results might be limited because this research was undertaken in a single center by orthodontic residents. The data analysis should also be circumscribed to the materials used in the present study.

\section{Conclusions}

In contrast to previous studies in young patients, in adults, bonding of orthodontic tubes to molars is similar to molar banding; however, both procedures had a high failure rate in the lower arch. 


\section{References}

1. Flores-Mir C. Bonded molar tubes associated with higher failure rate than molar bands. Evid Based Dent. 2011;12(3):84. doi:10.1038/sj.ebd.640081

2. Nazir M, Walsh T, Mandall NA, Matthew S, Fox D. Banding versus bonding of first permanent molars: a multi-centre randomized controlled trial. J Orthod. 2011;38(2):81-9. doi:10.1179/14653121141308

3. Boyd RL, Baumrind S. Periodontal considerations in the use of bonds and bands on molars in adolescents and adults. Angle Orthod. 1992;62(2):117-26. doi:10.1043/0003-3219(1992)062<0117:PCITUO>2.0.CO;2

4. Erverdi N, Kadir T, Ozkan H, Acar A. Investigation of bacteremia after orthodontic banding. Am J Orthod Dentofacial Orthop. 1999;116(6):687-90. doi:10.1016/S0889-5406(99)70205-2

5. McLaughlin JO, Coulter WA, Coffey A, Burden DJ. The incidence of bacteremia after orthodontic banding. Am J Orthod Dentofacial Orthop. 1996;109(6):639-44. doi:10.1016/S0889-5406(96)70076-8

6. Banks P, Macfarlane TV. Bonded versus banded first permanent molar attachments: a randomized clinical trial. J Orthod. 2007;34(2):128-6. doi:10.1179/146531207225022032

7. Millett DT, Mandall NA, Mattick RC, Hickman J, Glenny AM. Adhesives for bonded molar tubes during fixed brace treatment. Cochrane Database Syst Rev. 2011;(6):CD008236. doi:10.1002/14651858.CD008236.pub2

8. Millett DT, Hallgren A, Fornell AC, Robertson M. Bonded molar tubes: a retrospective evaluation of clinical performance. Am J Orthod Dentofacial Orthop. 1999; 115(6):667-74. doi:10.1016/S0889-5406(99)70293-3

9. Melo ACEO, Carneiro LOT, Pontes LF, Cecim RL, Mattos JNR, Normando D. Factors related to orthodontic treatment time in adult patients. Dental Press J Orthod. 2013;18(6):59-63. doi:10.1590/S2176-94512013000500011
10. Vercelino CRMP, Pinzan A, Gurgel JA, Bramante FS, Pinzan LM. In vitro study of shear bond strength in direct bonding of orthodontic molar tubes. Dental Press J Orthod. 2011;16(3):60.e1-8. doi:10.1590/S2176-94512011000300007

11. Chapman JL, Coreil MN, Armbruster PC, Du JX. Shear bond strengths of molar tubes bonded with different adhesives. Aust. Orthod. J. 2009;25(1):1-7.

12. Eliades T, Brantley WA. The inappropriateness of conventional orthodontic bond strength assessment protocols. Eur J Orthod. 2000;22(1):13-23. doi:10.1093/ejo/22.1.13

13. Gange P. The evolution of bonding in orthodontics. Am J Orthod Dentofacial Orthop. 2015;147(4 Suppl):S56-63. doi:10.1016/j.ajodo.2015.01.011

14. Geiger AM, Gorelick L, Gwinnett AJ. Bond failure rates of facial and lingual attachments. J Clin Orthod. 1983;17(3):165-9.

15. Millett DT, McCabe JF. Orthodontic bonding with glass ionomer cement: a review. Eur J Orthod. 1996;18(4):385-99. doi:10.1093/ejo/18.4.385

16. Pandis N, Christensen L, Eliades T. Long-term clinical failure rate of molar tubes bonded with a self-etching primer. Angle Orthod. 2005;75(6):1000-2.

17. Zachrisson BJ. A posttreatment evaluation of direct bonding in orthodontics. Am J Orthod. 1977;71(2):173-89. doi:10.1016/S0002-9416(77)90394-3

18. Jung MH. Survival analysis of brackets and tubes: a twelve-month assessment. Angle Orthod. 2014;84(6):1034-40. doi:10.2319/122613-946.1

19. Fleming PS, Eliades T, Katsaros C, Pandis N. Curing lights for orthodontic bonding: a systematic review and meta-analysis. Am J Orthod Dentofacial Orthop. 2013;143(4 Suppl):S92-103. doi:10.1016/j.ajodo.2012.07.018

20. Bichara LM, Aragón ML, Brandão GA, Normando D. Factors influencing orthodontic treatment time for non-surgical Class III malocclusion. J Appl Oral Sci. 2016;24(5):431-6. doi:10.1590/1678-775720150353 